\title{
The heat loss calculating methods of external walls in the buildings reconstruction
}

\author{
Varvara Vinnichenko ${ }^{1, *}$, Azat Gabitov ${ }^{2}$, Aleksandr $\mathrm{Salov}^{2}$, Askar Gaisin², and Dmitriy \\ Kuznetsov $^{2}$ \\ ${ }^{1}$ Kharkiv National University of Civil Engineering and Architecture, 61002, Sumska st. 40, Kharkiv, \\ Ukraine \\ ${ }^{2}$ Ufa State Petroleum Technological University, 450000, Mendeleeva St. 195, Ufa, Russia
}

\begin{abstract}
Heat loss analysis in cladding of brick buildings under reconstruction is presented. Thermograms obtained under thermovision inspection and window systems operating experience in conditions of the Republic of Bashkortostan are thoroughly studied. Live issue of increasing buildings energy performance in public utilities sector may largely be solved by replacement of existing window units made of wood to new PVC profile windows equipped with multi-glazed glass units both in brick and frame-panel old buildings. Significant heat loss occurs in junctions between the window frames and the wall in jamb areas. Therefore for the heat conduction matrix for the finite element is used the heat balance equation. Use of the software application to choose certain measures to eliminate the thermal bridges enables to get the thermotechnical calculations in the junction between the window and the exterior wall in the form of temperature fields. Practical recommendations for arrangement of heat insulation in junctions between the window frames and the wall to eliminate actual defects and for normal room conditions are made under examinations. To get the heat conduction matrix for the finite element we will use the heat balance equation.
\end{abstract}

\section{Introduction}

The majority of residential buildings using wooden windows was built in the $20^{\text {th }}$ century in the Soviet Union. Window constructions using PVC profile were being developed for the last 15 years due to strengthening of requirements to buildings heat protection and new technologies for making windows, with two-casement glass windows being replaced by single-casement equipped with glass units [1]. New domestic standards, regulating thermotechnical parameters for enclosing structures, that were applied in engineering and construction of new and reconstruction and renovation of available housing and public facilities were consistently toughening the requirements to thermal resistance all over the enclosing structures of buildings (walls, coating, windows, etc.).

\footnotetext{
* Corresponding author: vvinnichenko@ukr.net
} 


\section{Bibliography analysis}

Procedure to define the reduced heat-transfer resistance was improved by new SNiP (construction rules and regulations), thereby changing understanding of this value itself. Now the reduced heat-transfer resistance is to be understood as complex value characterizing the whole selected segment of envelope of the building considering all current non-homogeneities. So far, however, there is such a variety of engineering solutions for enclosing structures together with non-homogeneities peculiar thereto that the simplified geometric layout of heat-transfer inclusions specified in previous heat insulation regulatory documents cannot be used in making due calculations and engineering design [2]. Inconsistency of residential buildings, designed by SNiP 23-02-2003 before updating, with present standards by the reduced resistance values of external walls and by specific heat performance $[3,4]$ found by some scientists under analysis of cladding structural solutions is absolutely explained by this fact.

Various software applications [5,6] are currently applied for calculation of 2D and 3D temperature fields when defining the reduced heat-transfer resistance values of external walls. In 2015 SP 230.1325800.2015 "Enclosing structures of buildings. Thermal homogeneity characteristics" regulation containing reference tables of specific loss of heat through some standard heat-transfer inclusions for the most commonly used engineering solutions to external walls came into force. Good repeatability was demonstrated by the study in calculating results of the reduced heat-transfer resistance of the wall by temperature fields using both software applications [7, 8] and SP 230.1325800.2015 methods with reference tables.

\section{Materials and methods}

General problem to increase energy performance of buildings in public utilities sector may largely be solved by replacement of existing window units made of wood to new PVC profile windows equipped with multi-glazed glass units both in brick and frame-panel old buildings $[9,10]$.

However, replacement of window units is stipulated by some principal peculiarities:

- significant increase of high-shielding performance of a window unit occurs but due to reduction in frame thickness from $120 \mathrm{~mm}$ to $60-80 \mathrm{~mm}$ there is a risk of jamb freezing;

- PVC window unit exhibits minimum air permeability (i.e. sealed) thereby significantly (and not for the better) changing room air conditions;

- if the technology of window installation is violated, the area connecting translucent unit with the wall will be the thermal bridge.

Furthermore, increase of high-shielding performance of window units and sealing of junctions thereof together with current ventilation system lead to high humidity and if combined with window installation defects often result in freezing of joints between the window unit and the wall thereby leaving moisture and even frost on the jamb surface [11, 12]. Experimental evaluation of thermal and physical characteristics changes in exterior walls after installation of new windows with glass units was made through thermovision inspection (Fluke Ti20 thermal imager).

According to the thermograms (Fig.1.) temperature in the corners of the window area from the inside is $13^{\circ} \mathrm{C}$, revealing incorrect installation and freezing of junction between the window and exterior brick wall $[12,13]$. Similar defects are found under examination of residential and municipal facilities in the Republic of Bashkortostan. Junction between the window (new unit with narrow frame) and single-layer walls is found to be the weakest point in heat shielding. 

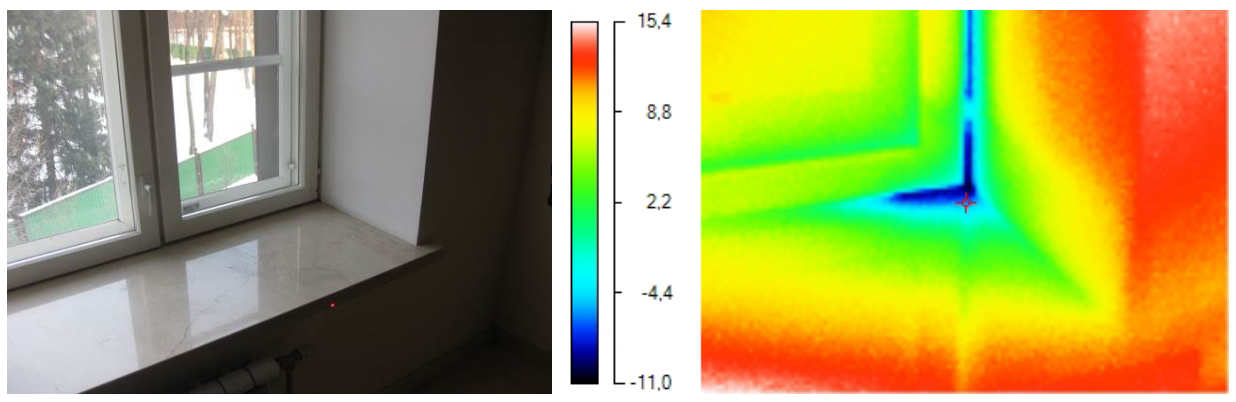

Fig.1. Window area thermogram.

The reason for this is heat loss by the window frame through the jambs. Window unit is in the negative temperature area in single-layer walls and heat is lost not only along the window frame but through the wall itself. This is not happened when the exterior wall is efficiently insulated and if combined with window frame insulation [14, 15].

Junction between the window unit and exterior wall of the building is quite complex and multi-element therefore its manual thermotechnical calculation by SP 50.133330 .2012 is difficult enough. Thermotechnical calculations made as per this standard may be done using the finite elements method (FEM) [16, 17]. In our case the finite element (junction between the wall and the window) is taken as a rectangle for making thermotechnical calculations. Mathematical tools are presented in [18] by the authors.

To get the heat conduction matrix for the finite element we will use the heat balance equation:

$$
\chi=\int_{V} \frac{1}{2}\left[\{g\}^{T}[D]\{g\}\right] d V+\int_{S} q T d s+\int_{s} \frac{1}{2} h\left(T-T_{\infty}\right)^{2} d S
$$

As function $T$ is not continuous in the whole area instead of it we will introduce function $T i$ defined on separate elements. Integral (1) will be broken into integrals by separate elements

$$
\chi=\sum_{i=1}^{n}\left(\int_{V^{i}}^{1} \frac{1}{2}\left[\left\{g^{i}\right\}^{T}\left[D^{i}\right]\left\{g^{i}\right\}\right] d V+\int_{S^{i}} q^{i} T^{i} d s+\int_{s^{i}} \frac{1}{2} h^{i}\left(T^{i}-T_{\infty}^{i}\right)^{2} d S\right)
$$

where, $n$ - total number of elements.

Substituting (1) to (2) we get the following:

$$
\left.\chi=\sum_{i=1}^{n}\left(\int_{V^{i}} \frac{1}{2}\{T\}^{T}\left[B^{e}\right]^{T}\left[D^{i}\right]\left[B^{e}\right]\{T\}\right] d V+\int_{S^{i}} q\left[B^{i}\right]\{T\} d S+\int_{S^{i}} \frac{1}{2} h^{i}\left(T^{i}-T_{\infty}^{i}\right)^{2} d S\right)
$$

If there is no convective heat exchange in the boundary and heat flow $q$ is equal to zero then (3) will be as follows

$$
\chi=\sum_{i=1}^{n}\left(\int_{V^{i}}^{1} \frac{1}{2}\{T\}^{T}\left[B^{e}\right]^{T}\left[D^{i}\right]\left[B^{e}\right]\{T\}\right] d V
$$

Heat conduction matrix for rectangular finite element will be defined from (4) by 


$$
R=\int_{-\frac{b}{2}-\frac{a}{2}}^{\frac{b}{2}} \int_{-\frac{a}{2}}^{\frac{a}{2}} B^{T} D B d x d y
$$

on integrating (5) the heat conduction matrix in tabular form will be as follows:

$$
\begin{array}{|c|c|c|c|}
\hline \frac{b}{a}+\frac{a}{b} & -\frac{b}{a}+\frac{a}{2 b} & \frac{b}{2 a}-\frac{a}{b} & -\frac{b}{2 a}-\frac{a}{2 b} \\
\hline \frac{k}{3}+\frac{b}{b} & -\frac{b}{2 a}-\frac{a}{2 b} & \frac{b}{2 a}-\frac{a}{b} \\
\hline & \frac{b}{a}+\frac{a}{b} & -\frac{b}{a}+\frac{a}{2 b} \\
\hline & & \frac{b}{a}+\frac{a}{b} \\
\hline
\end{array}
$$

The heat conduction matrix was run through the test case considering convective heat exchange, by making the heating pattern of the wall under the results thereof.

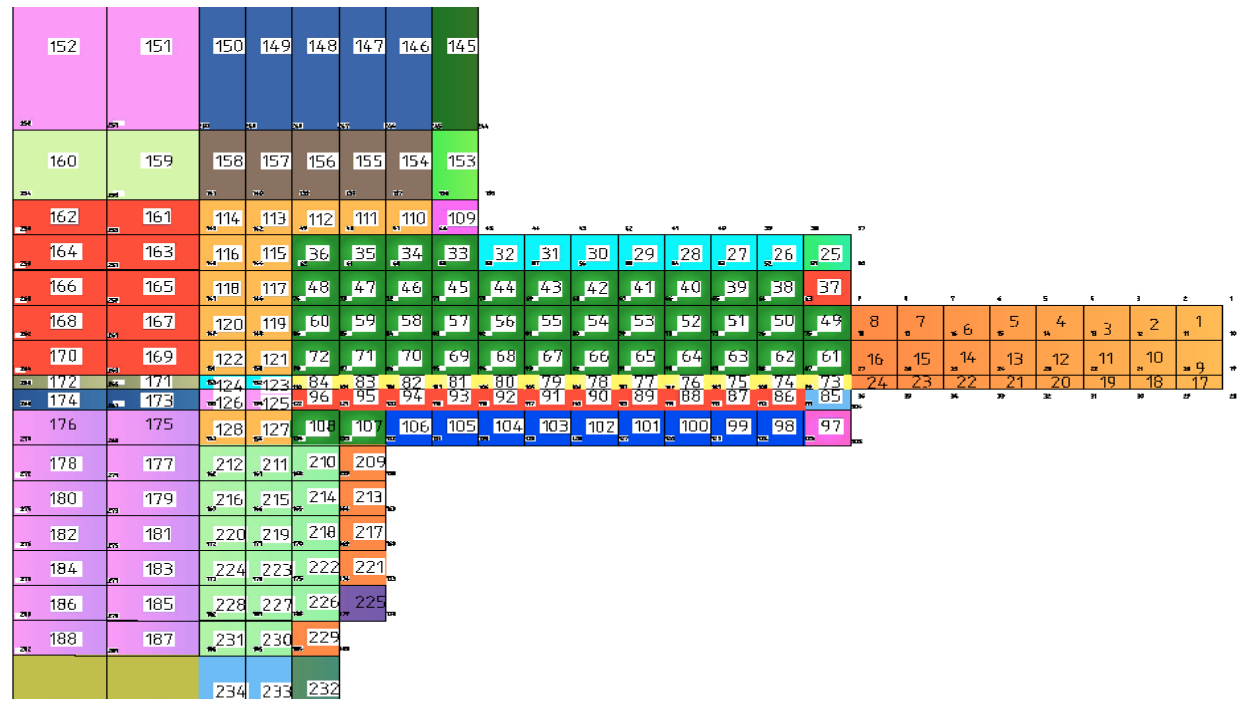

Fig.2. Computational model of a part of the wall with the window attached thereto.

According to analysis of the obtained data the dew point is inside the wall [19] (for the coldest five-day period of $-35^{\circ} \mathrm{C}$ ). Above mentioned method (Fig.2) was realized by "ASPECT" software application set up by authors of this research.

Thermotechnical calculations results for the junction between the window unit and the exterior wall of the building may be likely to be obtained using this software application as the temperature fields [20]. This application enables to define the coldest area for choosing certain measures to eliminate the thermal bridges thereby confirming the research results of various authors. The jamb appears to be in the negative temperature area according to the calculations made. 


\section{Conclusions}

In a number of cases significant heat loss is found to take place in jamb areas when analyzing heat loss in exterior walls of brick buildings. Experimental evaluation of thermal and physical characteristics changes in exterior walls after installation of new windows with glass units was made through thermovision inspection. Use of the software application [21] to choose certain measures to eliminate the thermal bridges enables to get the thermotechnical calculations in the junction between the window and the exterior wall in the form of temperature fields.

According to the study made the heat insulation placed in the junction between the window unit and the wall is the important element of the window frame to eliminate thermal bridges and for keeping normal room conditions.

\section{References}

1. A.I. Bedov, A.M. Gaysin, A.I. Gabitov, News of higher educational institutions. Textile industry technology, 3, 231-236 (2017)

2. A.M. Gaysin, M.V. Sharafutdinova, A.I. Gabitov, E.A. Udalova, History of science and technology, 10, 21-28 (2014)

3. A.M. Gaisin, V.V. Babkov, Construction materials, 1, 55-58 (2016)

4. A.S. Salov, L.I. Khabibullina, A.I. Gabitov, E.A. Udalova, V.A. Timofeev, A.A. Timofeev, History of science and technology, 11, 37-43 (2017)

5. A.I. Bedov, A.I. Gabitov, Bulletin of MSUCE, 328 (2017)

6. A.A. Semenov, A.I. Gabitov, Part 1 Static analysis M: Association of Construction Institutions Publishers, 152 (2005)

7. A.S. Salov, I.G. Terekhov, I.V. Nedoseko, Ufa USPTU Publishers, 138 (2016)

8. A.I. Bedov, A.S. Salov, A.I. Gabitov, D.V. Kuznetsov, E.A. Sadykova, International Journal for Computational Civil and Structural Engineering, 4, 37-46 (2017)

9. S.I. Kryshov, I.S. Kurilyuk, Housing construction, 7, 3-5 (2016)

10. A.M. Gaisin, R.R. Gareev, V.V. Babkov, I.V. Nedoseko, S.Y. Samokhodova, Construction materials, 4, 82-86 (2015)

11. A.I. Gabitov, E.A. Udalova, A.S. Salov, A.R. Chernova, D.V. Pyzhjanova, V.V. Yamilova, History of science and technology, 6, 58-65 (2017)

12. A.I. Bedov, V.V. Znamensky, A.I. Gabitov, Structural Assessment, Renovation and Strengthening of Frames of Operating Buildings and Structures. Part 1. Structural Survey and Assessment of Frames of Operating Buildings and Structures (M: ASV Press, 2014)

13. A.I. Bedov, A.I. Gabitov, V.V. Znamensky, Structural Assessment, Renovation and Strengthening of Frames of Operating Buildings and Structures. In two parts. Part 2. Structural Renovation and Strengthening of Frames of Operating Buildings and Structures (M: ASV Press, 2017)

14. A.I. Bedov, A.M. Gaisin, A.I. Gabitov, A.S. Salov, A.A. Gallyamov, Industrial and Civil Construction, 3, 58-63 (2017)

15. A.M. Gaisin, S.Y. Samokhodova, I.V. Nedoseko, A.Y. Paymetkina, Residential construction, 5, 36-40 (2016)

16. A.I. Bedov, A.I. Gabitov, A.S. Salov, A.M. Gaisin, L.I. Khabibullina, Building and reconstruction, 6(74), 3-12 (2017) 
17. A.I. Bedov, A.S. Salov, A.I. Gabitov, XXI International Scientific Conference on Advanced in Civil Engineering "Construction - The Formation of Living Environment", 365, 1-8 (2018)

18. A.I. Bedov, A.M. Gaisin, A.I. Gabitov, R.G. Galeev, A.S. Salov, M.S. Shibirkina, Bulletin of MSUCE, 11, 46-57 (2015)

19. A.I. Bedov, A.I. Gabitov, Engineering, Renovation and Strengthening of Masonry and Reinforced Masonry Structures (M.: ASV Press, 2006)

20. D.N. Sursanov, A.B. Ponomaryov, Bulletin of National Research Perm Polytechnic University Construction and Architecture, 4, 144-165 (2015)

21. R.G. Galeev, A.M. Gaisin, M.S. Shibirkina, D.A. Sinitsyn, A.S. Salov, Application for making thermotechnical calculation of junction between window unit and exterior wall of the building: certificate of computer software registration, patent 2016612591 (2016) 